\title{
EXTENSÃO DO PMV PARA AVALIAÇÃO DO CONFORTO TÉRMICO DE IDOSAS EM AMBIENTES COM VENTILAÇÃO NATURAL
}

\author{
PMV EXTENSION TO EVALUATE THERMAL COMFORT OF ELDERLY WOMEN IN NATURALLY \\ VENTILATED ROOMS
}

\author{
Raiana Spat Ruviaro ${ }^{1}$ \\ Bruna Zambonato ${ }^{2}$ \\ (Diane de Campos Grigoletti ${ }^{3}$ \\ ${ }^{1}$ Universidade Federal de Santa Maria, \\ Santa Maria, RS, Brasil, \\ raianasrarq@gmail.com \\ 2 Universidade Federal de Santa Maria, \\ Santa Maria, RS, Brasil, \\ zambonato.bruna@acad.ufsm.br \\ 3 Universidade Federal de Santa Maria, \\ Santa Maria, RS, Brasil, \\ giane.c.grigoletti@ufsm.br
}

Contribuição dos autores:

RSR: conceituação, curadoria de dados, análise formal, investigação, metodologia, administração de projetos, validação, visualização, escrita - rascunho original, escrita - revisão e edição. BZ: análise formal, investigação, metodologia, validação, visualização, escrita - rascunho original, escrita - revisão e edição. GCG: conceituação, curadoria de dados, análise formal, metodologia, administração de projetos, supervisão, validação, visualização, escrita - rascunho original, escrita - revisão e edição.

Fomento: Conselho Nacional de Desenvolvimento Científico e Tecnológico. Coordenação de Aperfeiçoamento de Pessoal de Nível Superior.

Conflito de interesse: declara não haver.

\begin{abstract}
Resumo
O envelhecimento populacional torna necessário criar condições para que idosos vivam com qualidade de vida. O conforto térmico das edificações é fundamental para atingir essa meta. Esta pesquisa analisou a aplicabilidade do Voto Médio Estimado (PMV) e a sua extensão (PMVe) para avaliação do conforto térmico de idosas, com idade igual ou superior a 60 anos. O estudo foi aplicado em dois residenciais geriátricos naturalmente ventilados localizados em Santa Maria, RS, região de clima temperado com verão quente. As variáveis ambientais temperatura do ar, umidade relativa do ar, temperatura de globo e velocidade do ar foram medidas e foram aplicados questionários para o levantamento da sensação e preferência térmicas das idosas e das variáveis vestimenta e atividade metabólica. Então, calculou-se o índice de sensação de conforto. A sensação térmica real dos usuários foi comparada com o PMV e o PMVe, com fatores de correção de 0,5, 0,7 e 0,9. Comparando os três valores de PMVe, estimou-se que, quanto menor o fator expectativa, menor é a diferença entre PMVe e sensação térmica para valores negativos (frio). O PMVe com fator de correção 0,5 apresentou perfeita correlação das variáveis PMV e sensação térmica relatada em 11,54\% das medições, já o PMVe de 0,7 e de 0,9 não apresentaram nenhum ponto sobre a reta de referência. O estudo mostrou que a extensão do PMV não corrige as imprecisões do modelo, mas reduz as diferenças encontradas com os valores de sensação térmica relatada, diminuindo a superestimação da sensação de frio que o PMV resultava para as idosas.
\end{abstract}

Palavras-chave: Conforto térmico. Idosas. PMV.

\begin{abstract}
The aging of the population requires creating conditions for the elderly to live with quality. Buildings' thermal comfort is essential to achieve this goal. This research analyzes the Predicted Mean Vote (PMV) and its extension (PMVe) to assess elderly women's thermal comfort conditions, aged 60 years or above. The study was conducted in two naturally ventilated senior homes in Santa Maria, RS, region with a temperate climate and hot summer. The study measured air temperature, air relative humidity, globe temperature, and air velocity. The study also performed a data survey on the perception and thermal preferences, clothing, and metabolic activity of the elderly. Then, the comfort sensation index was calculated. Users' thermal sensation was compared with PMV and PMVe, considering expectation factors of $0.5,0.7$, and 0.9. Comparing the three PMVe values, we could estimate that the lower the expectation factor, the smaller the difference between the PMVe and the negative thermal sensation votes (cold). The PMVe with correction factor 0.5 presented a perfect correlation for the PMV variables and the thermal sensation to $11.54 \%$ of the measurements. In contrast, the PMVe of 0.7 and 0.9 showed no points over the correlation reference line. The study demonstrated that the PMV extension does not correct the PMV inaccuracies but reduces the thermal sensation's differences, reducing the cold sensation overestimation of PMV results for elderly women.
\end{abstract}

Keywords: Thermal comfort. Elderly women. PMV.

Editor Responsável:

Letícia de Oliveira Neves (D)

How to cite this article:

RUVIARO, R. S.; ZAMBONATO, B.; GRIGOLETTI, G. de C. Extensão do PMV para avaliação do conforto térmico de idosas em ambientes com ventilação natural. PARC Pesquisa em Arquitetura e Construção, Campinas, SP, v. 12, p. e021002, 2021. DOI: http://dx.doi.org/10.20396/parc.v12i00.8658443 


\section{Introdução}

O envelhecimento populacional - com previsão de um a cada seis indivíduos ter mais de 65 anos em 2050 (NAÇÕES UNIDAS, 2019), representando 16\% da população mundial, aponta a importância crescente dessa parcela da população. A população idosa está entre os grupos de maior risco a variações ambientais (WHO, 2018). A mortalidade relacionada aos efeitos do calor e do frio é maior entre idosos (ABOUBAKRI et al., 2020; SON et al., 2016). A vulnerabilidade dessa população tem ligação com a diferença de percepção de conforto térmico em relação a outras faixas etárias. $O$ envelhecimento pode afetar fatores fisiológicos que alteram a sensibilidade térmica e a capacidade de detectar e responder a variações de temperatura, bem como a adaptação psicológica e física ao entorno (BAQUERO LARRIVA; HIGUERAS GARCíA, 2019). Ainda, este grupo comumente depende de terceiros para adaptar-se às condições ambientais.

A taxa metabólica de idosos pode chegar a 70\% do valor para jovens (TSUZUKI; OHFUKU, 2002), podendo atingir níveis menores que $50 \mathrm{~W} / \mathrm{m}^{2}$ (TSUZUKI; IWATA, 2002). A redução do metabolismo dificulta o aquecimento do corpo, fazendo com que idosos tenham a tendência de preferir ambientes com temperaturas mais altas (PANET; ARAÚJO; ARAÚJO, 2020; TSUZUKI; OHFUKU, 2002). Os mecanismos de termorregulação também são afetados, havendo redução da capacidade de sudorese, da capacidade de transporte de calor do corpo para a pele, dos níveis de hidratação, da vasodilatação e vasoconstrição (HAVENITH, 2001). O uso de medicamentos, comum para idosos visto que a maioria apresenta enfermidades crônicas, também pode afetar a termorregulação (BAQUERO LARRIVA; HIGUERAS GARCÍA, 2019). A sua sensibilidade térmica é reduzida, necessitando de estímulos mais intensos para perceber a necessidade de adaptar-se às condições climáticas, o que pode ter relação com a maior frequência de hipotermia ou hipertermia em idosos (KRÜGER; ROSSI, 2011). Além disso, idosos tendem a apresentar respostas fisiológicas como suor e tremor para níveis respectivamente mais altos e mais baixos de temperatura (ANDERSON; MENEILLY; MEKJAVIC, 1996).

A população idosa passa a maior parte do seu tempo em ambientes internos, seja em suas próprias residências, em residências de familiares ou em instituições asilares de longa permanência. No entanto, tais edificações não costumam ser adaptadas às suas necessidades, causando insegurança e maior dependência física. A preocupação repercute, portanto, nas edificações e no quanto elas garantem o conforto térmico dos idosos. O conforto térmico é definido pela sensação humana expressa na satisfação com o ambiente térmico, dependendo, principalmente, de fatores físicos, fisiológicos e psicológicos (ASHRAE, 2017). Para a população idosa, a exposição a condições inapropriadas de conforto térmico pode ocasionar doenças ou agravar seu estado de saúde (HAVENITH, 2001; KENEY; MUNCE, 2003; LEVVA; BERMAN; DAVIDSON, 2017).

O PMV, desenvolvido por Fanger (1970), é um dos índices de conforto térmico mais utilizados mundialmente desde a sua criação. O modelo considera as principais variáveis de influência na sensação de conforto térmico: temperatura do ar, temperatura radiante média, umidade relativa do ar, velocidade do ar, vestimenta e atividade metabólica. Por ter sido desenvolvido para ambientes climatizados artificialmente, quando aplicado em edificações não climatizadas, apresenta uma sensação térmica de maior calor do que os ocupantes relatam (BRAGER; DEAR, 1998). Uma das explicações para esta diferença pode ser a expectativa dos ocupantes (FANGER; TOFTUM, 2002). 
A fim de adaptar o modelo para estas situações, Fanger e Toftum (2002) desenvolveram uma extensão do modelo, PMVe, expresso por um fator de expectativa e que é multiplicado pelo PMV para atingir a sensação térmica real de ocupantes em edificações não condicionadas artificialmente em climas quentes. Os autores ainda indicam uma redução de $6,7 \%$ na taxa metabólica para cada escala do PMV, sugerindo que as pessoas tendem a reduzir suas atividades e, consequentemente, o metabolismo em ambientes quentes. Sousa (2018) comparou o modelo adaptativo, o PMV e sua extensão, utilizando dados de adultos com diferentes históricos térmicos no semiárido paraibano. $O$ índice com melhores resultados para a predição de conforto foi a extensão do PMV para climas quentes calculado apenas com o fator expectativa, tanto para ambientes com ventilação natural quanto para condicionados artificialmente, independente do histórico térmico das pessoas.

Estudos referentes ao conforto térmico, com foco no público idoso, estão sendo realizados em diversos países. Em Portugal, por exemplo, na cidade de Porto, Mendes et. al (2017) avaliaram os índices de conforto térmico de idosos em residenciais geriátricos no inverno. Foram medidas as variáveis térmicas e aplicado um questionário para levantamento do PMV e porcentagem de pessoas insatisfeitas (PPD) dos idosos. O PMV demonstrou valores de levemente frio $(-1)$ a frio $(-2)$, um alto percentual de ocupantes em desconforto (64\%) e que os idosos preferem temperaturas mais altas que jovens e adultos, com temperatura ótima de $25,3{ }^{\circ} \mathrm{C}$, enquanto a zona de conforto para adultos é de 20 a $24{ }^{\circ} \mathrm{C}$. Também no Reino Unido, em Bath, Hughes e Natarajan (2019) avaliaram residenciais geriátricos ventilados naturalmente, no verão e em ondas de calor. Os resultados do PMV sugeriram que os idosos sentiram frio (-1 e -2), enquanto a sensação térmica real sugeria que se sentiam confortáveis, com $91 \%$ dos votos entre -1 e +1 , apresentando baixa correlação (de $54 \%$ a $29 \%$ ) entre os votos levantados por meio de questionários e os votos calculados por PMV. Em estudo similar, no inverno, $87 \%$ dos votos de sensação térmica levantados eram pelo menos um voto acima do PMV calculado e estavam entre $-1 \mathrm{e}+1 \mathrm{em} 79 \%$ dos residenciais (HUGHES et al., 2019).

No Brasil, Montanheiro (2016) avaliou se as alterações existentes na sensação térmica de idosos em relação ao PMV calculado para indivíduos jovens nas mesmas condições climáticas eram significativas. As sensações térmicas reais relatadas pelos idosos foram estatisticamente similares às calculadas pelo PMV para as faixas de -1 , 0 e 1 (probabilidade de 3,489-10 para -1 e o, e de 9,89-5 para o e 1). No entanto, a precisão do índice PMV foi reduzida em situações de leve desconforto ou de desconforto tanto para frio quanto para calor (probabilidade de 1 para -2 e -1, e de 0,006 para 1 e 2), sugerindo que o PMV seria aplicável na faixa de $-1 \mathrm{a}+1$, mas quando o desconforto era maior, o PMV não representaria a sensação real. $O$ estudo foi realizado apenas para o período de verão, na cidade de Bauru, abrindo espaço para discussões e novas pesquisas no país.

Panet (2018) avaliou o conforto térmico de idosos em ambientes residenciais e propôs o primeiro índice de sensação térmica para idosos no semiárido paraibano. A sensação térmica da população analisada mostrou ser mais sensível ao frio e menos sensível ao calor. A preferência térmica de idosos apresentou tendência a ambientes mais aquecidos, possivelmente devido à influência da redução da sensibilidade do corpo ao calor (PANET; ARAÚJO; ARAÚJO, 2020). A autora aponta ainda para a necessidade de estudos semelhantes com este grupo etário em regiões distintas do Brasil.

Esta pesquisa busca contribuir com o tema analisando a aplicabilidade do PMV e da extensão do PMV (PMVe) para climas quentes na avaliação do conforto térmico da população idosa feminina em clima temperado com verão quente. Avaliou-se a 
correlação da sensação térmica relatada pelas idosas com os valores calculados pelo PMV e pelo PMVe em três ambientes de sala de estar de dois edifícios residenciais geriátricos de Santa Maria, RS, com o intuito de verificar se o modelo é explicativo ou não dos dados levantados.

A opção por idosas deve-se ao fato de mulheres viverem mais do que homens. Em 2016, a expectativa de vida dos homens era 72,2 anos, enquanto a das mulheres era 79,4 anos (IBGE, 2017). As alterações causadas com o envelhecimento são mais significativas para mulheres devido a características corporais (GUYTON; HALL, 2010). Além disso, são mais sensíveis a temperaturas mais baixas do que os homens (PARSONS, 2002), e apresentam maior desconforto térmico (GRIEFAHN; KUNEMUND, 2001; KARJALAINEN, 2007). No presente estudo, as idosas encontravam-se em atividade estacionária ocupando ambientes ventilados naturalmente em residenciais geriátricos. Buscou-se abranger um número significante de participantes, com pessoas de diferentes histórias, culturas, condições educacionais e estilos de vida, visto que a vivência de cada indivíduo reflete na avaliação do conforto dos ambientes (DEAR; BRAGER; COOPER, 1997).

\section{Método}

A pesquisa, de natureza empírica, adotou a associação de múltiplos métodos, com três instrumentos de investigação: medições das variáveis ambientais, aplicação de questionário e obtenção das variáveis pessoais (taxa metabólica e isolamento térmico) por meio de dados antropométricos e de planilha de peças do vestuário em uso pelas idosas no momento da aplicação do questionário. Os procedimentos utilizados foram: caracterização do objeto de estudo; pesquisa de campo; cálculo das variáveis pessoais; medições das variáveis ambientais; cálculo dos índices de conforto e análise de dados.

\section{Caracterização do objeto de estudo}

As edificações pesquisadas estão localizadas em Santa Maria, na região central do estado do Rio Grande do Sul, a aproximadamente $300 \mathrm{~km}$ da capital Porto Alegre. A região pertence à Zona Bioclimática 2 (ABNT, 2005) e apresenta clima temperado, com ocorrência de precipitação em todos os meses do ano e verão quente, do tipo Cfa, de acordo com a Classificação de Köppen-Geiger (KUINCHTNER; BURIOL, 2001). O mês de janeiro é o mais quente, com temperaturas médias acima de $24{ }^{\circ} \mathrm{C}$ e média das máximas de $32{ }^{\circ} \mathrm{C}$, enquanto o mês mais frio, julho, apresenta temperaturas médias entre $13{ }^{\circ} \mathrm{C}$ e $15^{\circ} \mathrm{C}$ e média das mínimas entre $7{ }^{\circ} \mathrm{C}$ e $10^{\circ} \mathrm{C}$ (SARTORI, 2000). A região tem precipitação anual entre 1.500 e 1.700 mm, distribuída em 90 a 110 dias de chuva ao longo do ano, e umidade relativa do ar entre 50 e $89 \%$ (ROSSATO, 2011).

O ano de 2017, período da coleta de dados, caracterizou-se como atípico, com inverno mais quente e primavera mais fria que o padrão. O Rio Grande do Sul apresentou o final de inverno, primavera e início de verão com chuvas abaixo do padrão climatológico. As temperaturas máximas ficaram acima do padrão de junho a setembro e em dezembro, enquanto outubro e novembro apresentaram temperaturas máximas abaixo do padrão. Quanto às temperaturas mínimas, de julho a setembro ficaram acima do padrão climatológico e nos meses de outubro e novembro abaixo do padrão, conforme boletins climáticos, considerando a região central do estado do Rio Grande do Sul (INMET, 2020).

Os residenciais estudados são a Associação Amparo Providência Lar das Vovozinhas, instituição filantrópica que abriga 190 idosas, e o Longevità Casa para Idosos, instituição particular que abriga nove idosas. Os critérios de seleção para os edifícios pesquisados foram disponibilidade e interesse dos residenciais na pesquisa, que 
fossem ocupados por idosas não acamadas e com saúde física e mental, sem mobilidade comprometida e capazes de executar as atividades da vida diária. Foram pesquisadas três salas de estar: duas salas no Lar das Vovozinhas e uma no Longevità. A opção da pesquisa em salas de estar ocorreu devido ao maior número de idosas presentes simultaneamente, nas mesmas condições ambientais, bem como por serem espaços menos íntimos do que dormitórios. As medições foram realizadas de agosto a dezembro de 2017, compreendendo o final do inverno e toda a primavera, meses em que não costumam ocorrer as temperaturas máximas e mínimas anuais, evitando o possível uso do condicionamento artificial de ar, para que os ambientes se mantivessem ventilados naturalmente durante as medições. Os ambientes mantiveram sua configuração inicial para não modificar a aclimatação natural das usuárias.

A edificação do Lar das Vovozinhas possui 2 pavimentos, com paredes em alvenaria, lajes em concreto entre pavimentos e cobertura em telha de zinco. A sala do térreo possui somente uma fachada voltada ao exterior, já a sala do $2^{\circ}$ pavimento não possui nenhuma fachada voltada ao exterior. As Figuras 1 e 2 mostram as plantas baixas do residencial.

Figura 1 - Planta baixa térreo do Lar das Vovozinhas

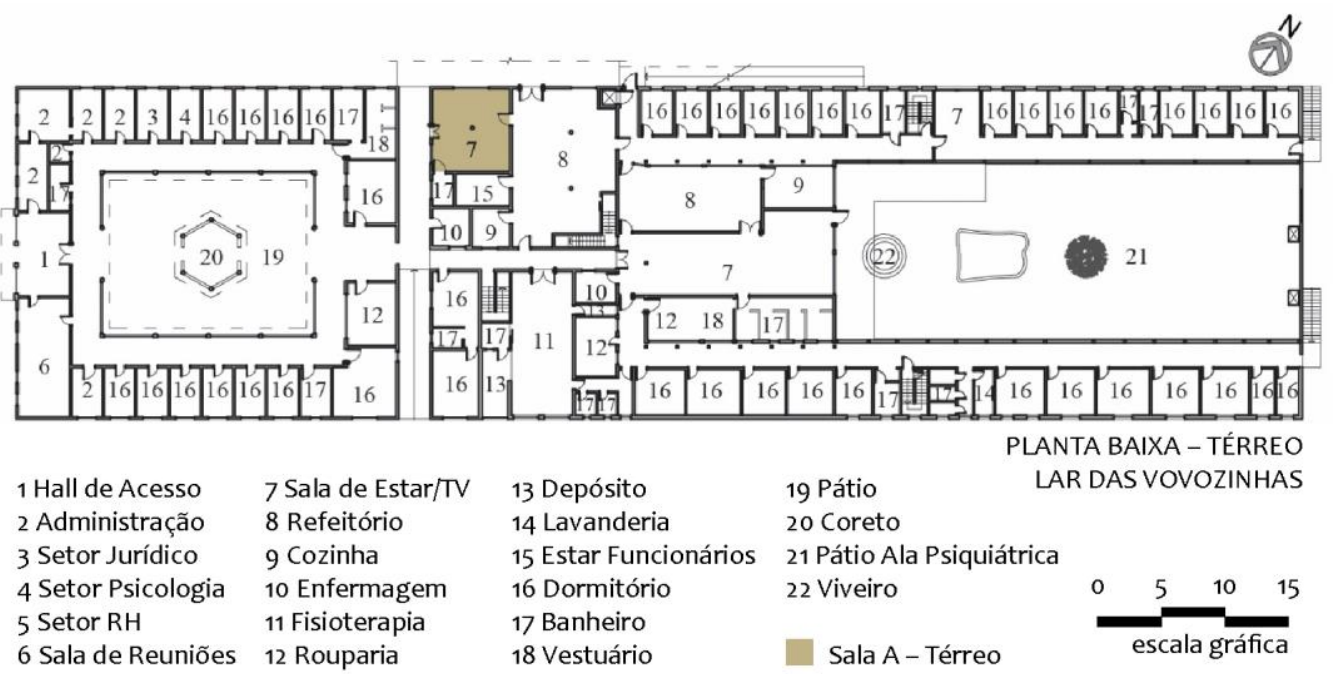

Fonte: Ruviaro (2018).

Figura 2 - Planta baixa 2o pavimento do Lar das Vovozinhas

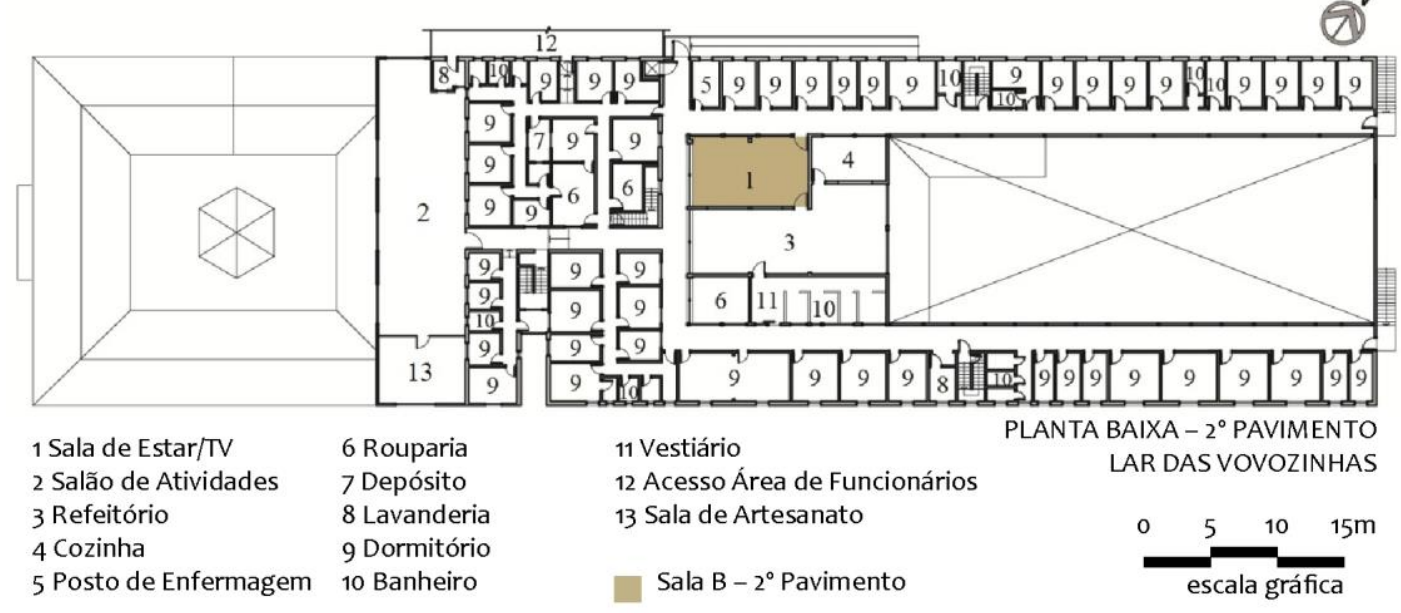

Fonte: Ruviaro (2018). 
A sala de estar do térreo, chamada de Sala de Estar A, tem janelas voltadas a noroeste, para uma área externa coberta, e sudoeste, para uma circulação coberta. Com 20 lugares, possui um ar condicionado, um ventilador de coluna e um aquecedor, operados por funcionários do residencial de acordo com a demanda das idosas, que se mantiveram desligados em todas as medições. A sala de estar do segundo pavimento, chamada de Sala de Estar B, não possui aberturas para a área externa, somente vãos voltados ao refeitório e janelas voltadas aos corredores de circulação (ventilação indireta). Com 23 lugares, a sala possui três ventiladores, posicionados próximos à laje de forro, operados por funcionários do residencial de acordo com a demanda das idosas, que estiveram ligados em quatro medições (medições 2, 4, 22 e 25, dias 28 de agosto, 4 de setembro, 20 de novembro e 11 de dezembro, respectivamente), já que circulava pouca ventilação natural.

A edificação do Longevità possui dois pavimentos, com cobertura em telha cerâmica e fechamento em platibanda. As paredes são de alvenaria, a laje em concreto entre pavimentos e é sombreada por árvores e edificações vizinhas. A Figura 3 ilustra o pavimento térreo.

Figura 3 - Planta baixa térreo Longevità

1 Hall
2 Sala de Estar/TV
3 Salão de Jantar
4 Posto de Enfermagem
5 Cozinha
6 Dormitório
7 Rouparia
8 Banheiro
Sala C

Sala C

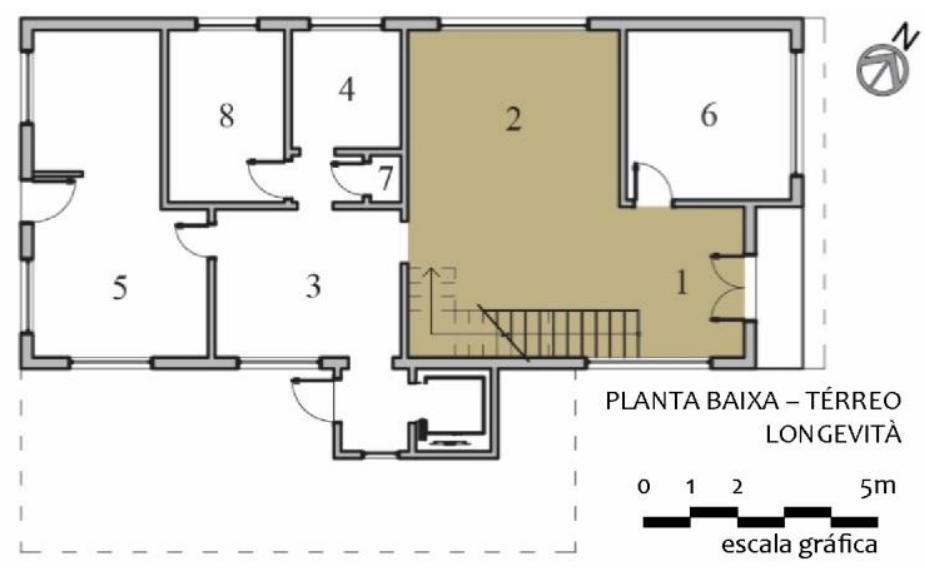

Fonte: Ruviaro (2018).

A sala de estar do Longevità, chamada de Sala de Estar C, possui janelas voltadas a noroeste e sudeste, que abrem para o exterior, recebendo ventilação e iluminação naturais. Com 8 lugares, a sala possui um climatizador móvel, operado por funcionários do residencial de acordo com a demanda das idosas, desligado durante as medições.

\section{Pesquisa de campo}

Os questionários (Quadro 1) foram aplicados por meio de entrevista estruturada às idosas nos três ambientes durante o mesmo período do ano (em 17 dias não consecutivos entre agosto e dezembro de 2017). As salas A e B foram visitadas nos mesmos dias, por pertencerem ao mesmo residencial, e a sala $C$ foi visitada em outro dia, na mesma semana, buscando manter condições térmicas semelhantes e comparativas. As aplicações ocorreram à tarde, entre $14 \mathrm{~h}$ e $17 \mathrm{~h}$, uma vez por semana de agosto a outubro, e uma vez a cada quinze dias de novembro a dezembro. Alternou-se o espaçamento entre as aplicações, pois as respostas do questionário repetiam-se e as idosas começaram a apresentar indisposição para participar da pesquisa. A medição e levantamento de dados dos três ambientes ocorreram 26 vezes (9 dias nas salas A e B, e 8 dias na sala C), totalizando 240 questionários aplicados. 
Os procedimentos realizados foram aprovados pelo Comitê de Ética em Pesquisa com Seres Humanos da Universidade Federal de Santa Maria (CAAE 69011317.0.0000.5346), com a finalidade de assegurar os princípios éticos do trabalho. A seleção das idosas contou com o conhecimento das cuidadoras de cada residencial, tendo em vista que precisavam ser aptas a responder à pesquisa. Na coleta de dados, 27 idosas participaram na Sala A, 27 idosas na Sala B e 7 na Sala C, totalizando 61 idosas. Entre as respondentes, 8 mulheres tinham idade abaixo de 60 anos, residentes do Lar, pois a instituição abriga também pessoas necessitadas. As respostas destas foram desconsideradas e somente 53 idosas se encaixaram no grupo de interesse. Foram desconsideradas também as respostas que desviaram do PMV acima de 2,5. Dos 240 questionários, 26 foram respondidos por participantes com idade inferior a 60 anos e 14 tiveram desvio maior que 2,5, resultando em 200 questionários válidos.

\begin{tabular}{|c|c|}
\hline $\begin{array}{l}1 \text { - Neste momento, como você está se sentindo } \\
\text { (sensação)? }\end{array}$ & $\begin{array}{l}\text { 2- Neste momento, como você gostaria de estar } \\
\text { (preferência)? }\end{array}$ \\
\hline $\begin{array}{l}\square \text { Com muito calor } \\
\square \text { Com calor } \\
\square \text { Só com u pouco de calor } \\
\square \text { Em bem-estar } \\
\square \text { Só com um pouco de frio } \\
\square \text { Com frio } \\
\square \text { Com muito frio }\end{array}$ & $\begin{array}{l}\square \text { Bem mais quente } \\
\square \text { Mais quente } \\
\square \text { Só um pouco mais quente } \\
\square \text { Estou bem } \\
\square \text { Só um pouco mais frio } \\
\square \text { Mais frio } \\
\square \text { Bem mais frio }\end{array}$ \\
\hline $\begin{array}{l}\text { 3- No inverno, o que você faz para se sentir mais } \\
\text { confortável? }\end{array}$ & $\begin{array}{l}4 \text { - No verão, o que você faz para se sentir mais } \\
\text { confortável? }\end{array}$ \\
\hline $\begin{array}{l}\square \text { Liga o ar condicionado/estufa/aquecedor } \\
\square \text { Fecha janelas/portas } \\
\square \text { Muda de lugar no ambiente (cadeira para sofá, fica } \square \\
\text { próxima de janela com sol) } \\
\square \text { Bebe café/chá/bebida quente } \\
\square \text { Toma banho quente } \\
\square \text { Coloca casaco/cobertor/meias/manta de lã } \\
\square \text { Outro: }\end{array}$ & $\begin{array}{l}\square \text { Liga o ar condicionado } \\
\square \text { Abre as janelas/portas } \\
\square \text { Liga o ventilador } \\
\square \text { Abana-se com leque } \\
\square \text { Muda de lugar no ambiente (sofá para cadeira, fica } \\
\text { próxima de janela com vento) } \\
\square \text { Bebe água/suco/bebida gelada } \\
\square \text { Toma banho frio } \\
\square \text { Coloca roupa mais leve } \\
\square \text { Outro: }\end{array}$ \\
\hline
\end{tabular}

Fonte: adaptado de Ruviaro (2018).

Além da aplicação da escala de sete valores do PMV, foram feitas duas perguntas que abordavam as alternativas que as idosas utilizam para se sentir mais confortáveis no verão e no inverno (como vestir roupas mais quentes, ligar o ventilador, por exemplo).

Antes do questionário, as entrevistadas estavam em repouso, sentadas, a mais de 30 minutos. Portanto, os dados foram recolhidos após mais de uma hora do almoço, como realizado em estudos similares (MONTANHEIRO, 2016; PANET, 2018). Juntamente com os questionários, foram levantadas as variáveis pessoais e ambientais.

\section{Cálculo das variáveis pessoais}

A vestimenta foi levantada pela composição de roupa de cada idosa em cada dia para cálculo do clo, com valores da ASHRAE (2017) para peças do vestuário. Para as idosas em poltronas ou sofás, o mobiliário foi considerado para o cálculo, aumentando em 0,2 clo, pois afetam o valor de isolamento da vestimenta (DEAR, BRAGER, COOPER, 1997).

Para a atividade metabólica, foi considerado o cálculo específico da taxa metabólica de cada participante, visto que os valores tabelados em normativas como a ISO 8996 (ISO, 2004), a ISO 7730 (ISO, 2005) e a ASHRAE Standard 55 (2017) referem-se a adultos, sugerindo que para idosos seja considerado valor inferior, pois as condições antropométricas afetam esta variável. Portanto, foram coletadas informações com as nutricionistas dos estabelecimentos sobre peso, altura e idade para o cálculo da taxa 
metabólica de repouso (TMR) de cada idosa pela Equação 1 (MIFFLIN et al., 1990). Esta foi a equação mais próxima à taxa metabólica medida dentre as equações avaliadas por Reidlinger, Willis e Whelan (2015) para idosos saudáveis com 70 anos ou mais e por Bonganha et al. (2013) para mulheres brasileiras em período de pós-menopausa, não obesas e fisicamente inativas entre 40 e 60 anos.

TMR=9,99×peso $(\mathrm{kg})+6,25 \times$ altura $(\mathrm{cm})-4,92 \times$ idade $($ anos $)+166 \times$ sexo -161

Eq. 1

Onde:

TMR é a taxa metabólica em repouso (kcal.dia-1); e

Sexo assume valores masculino $=1 ;$ feminino $=0$.

A TMR foi multiplicada por 1,5, referente ao fator de ajuste para o nível de atividade desempenhado: muito leve (sentado, em pé) (MAHAN; STUMP, 1998). A unidade do gasto energético é dada em $\mathrm{kcal} / \mathrm{dia}$, assim, o resultado foi dividido por 24 horas, para transformá-lo em $\mathrm{kcal} / \mathrm{h}$. Posteriormente a TMR foi dividida pela respectiva área da superfície corporal de cada idosa, calculada pela Equação 2 (ASHRAE, 2009). A relação da TMR pela ADU resultou na TMT, dada em $\mathrm{kcal} / \mathrm{h} . \mathrm{m}^{2}$, convertida para met.

$A D u=0,202 \times m 0,425 \times 10,725$

Eq. 2

Onde:

ADu é a área da superfície corporal, ou área de DuBois $\left(\mathrm{m}^{2}\right)$;

$\mathrm{m}$ é a massa do corpo $(\mathrm{kg})$; $\mathrm{e}$

l é a altura do corpo $(\mathrm{m})$.

\section{Medições das variáveis ambientais}

As variáveis ambientais medidas foram temperatura do ar, umidade relativa do ar, velocidade do ar e temperatura de globo, verificadas em todos os dias que foram aplicados os questionários. A temperatura de globo foi convertida para temperatura radiante média por meio da Equação 3, recomendada pela ISO 7726 (ISO, 1998), como utilizada em estudos similares (PANET, 2018; SOUSA, 2018), a qual parte do princípio do balanço das trocas térmicas entre o globo e o ambiente ao seu redor, considerando a convecção forçada, para globo padronizado com diâmetro de $15 \mathrm{~cm}$ e emissividade do globo negro (adimensional) de 0,95 , correspondente a pintura superficial externa negra.

$T_{r m}=\left[\left(T_{g}+273\right)^{4}+2,5 \times 10^{8} \times V_{a}^{0,6} \times\left(T_{g}-T_{a}\right)\right]^{0,25}-273$

Eq. 3

Onde:

$\mathrm{T}_{\mathrm{rm}}$ é a temperatura radiante média $\left({ }^{\circ} \mathrm{C}\right)$;

$\mathrm{T}_{\mathrm{g}}$ é a temperatura de globo $\left({ }^{\circ} \mathrm{C}\right)$;

$V_{a}$ é a velocidade do $\operatorname{ar}(\mathrm{m} / \mathrm{s}) ;$ e

$\mathrm{T}_{\mathrm{a}}$ é a temperatura do $\operatorname{ar}\left({ }^{\circ} \mathrm{C}\right)$.

Os instrumentos de medição utilizados foram: três registradores HOBO UX100-023 External Temp/RH Data Logger, para ambientes internos, com sensores de temperatura e umidade do ar externos ao corpo do equipamento; anemômetro de palhetas Instrutherm AD-155 (velocidade do ar); e termômetro de globo digital TGD100 marca Instrutherm (temperatura de globo). As Figuras 4, 5 e 6 mostram os pontos onde foram localizados os instrumentos de medição. 
RUVIARO, R. S.; ZAMBONATO, B.; GRIGOLETTI, G. de C.

Extensão do PMV para avaliação do conforto térmico de idosas em ambientes com ventilação natural

Figura 4 - Planta baixa Sala A: posicionamento dos equipamentos - ar condicionado, aquecedor e ventilador de coluna inoperantes em todas as medições

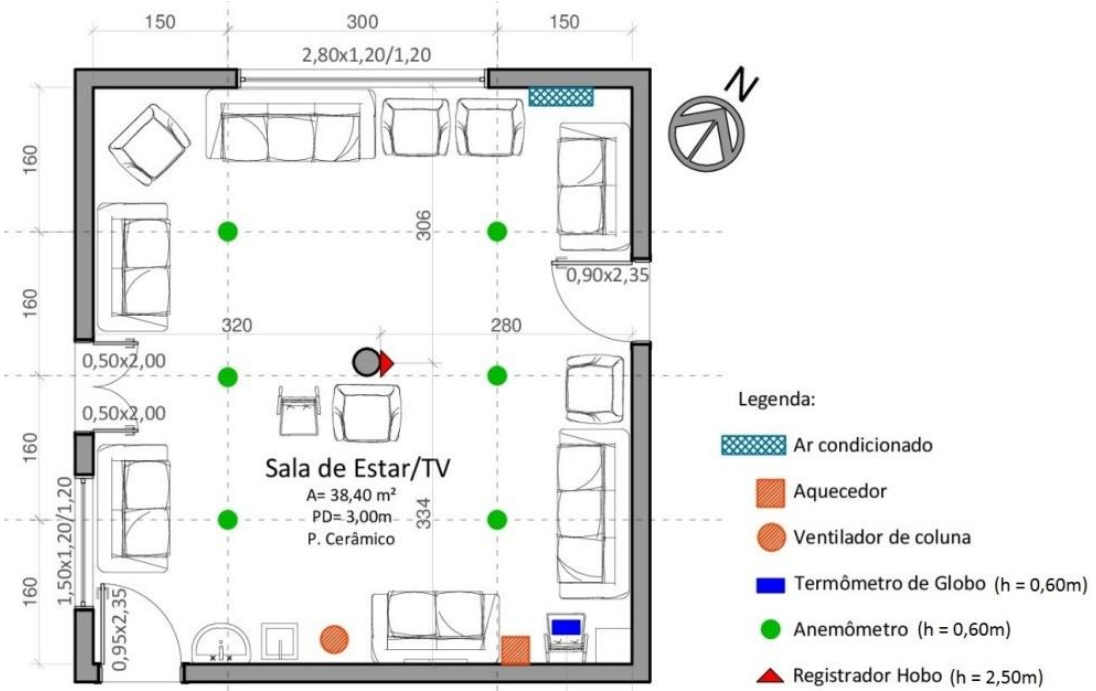

Fonte: Ruviaro (2018).

Figura 5 - Planta baixa Sala B: posicionamento dos equipamentos - ventiladores indicados por 1,2 e 3 operantes nas medições 2, 4, 22 e 25

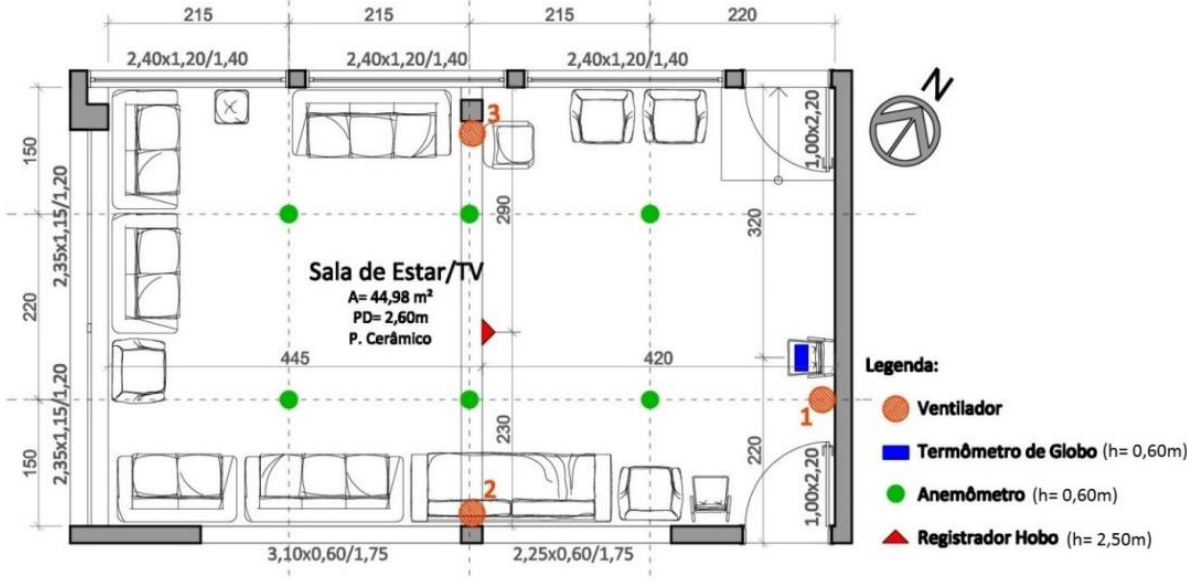

Fonte: Ruviaro (2018).

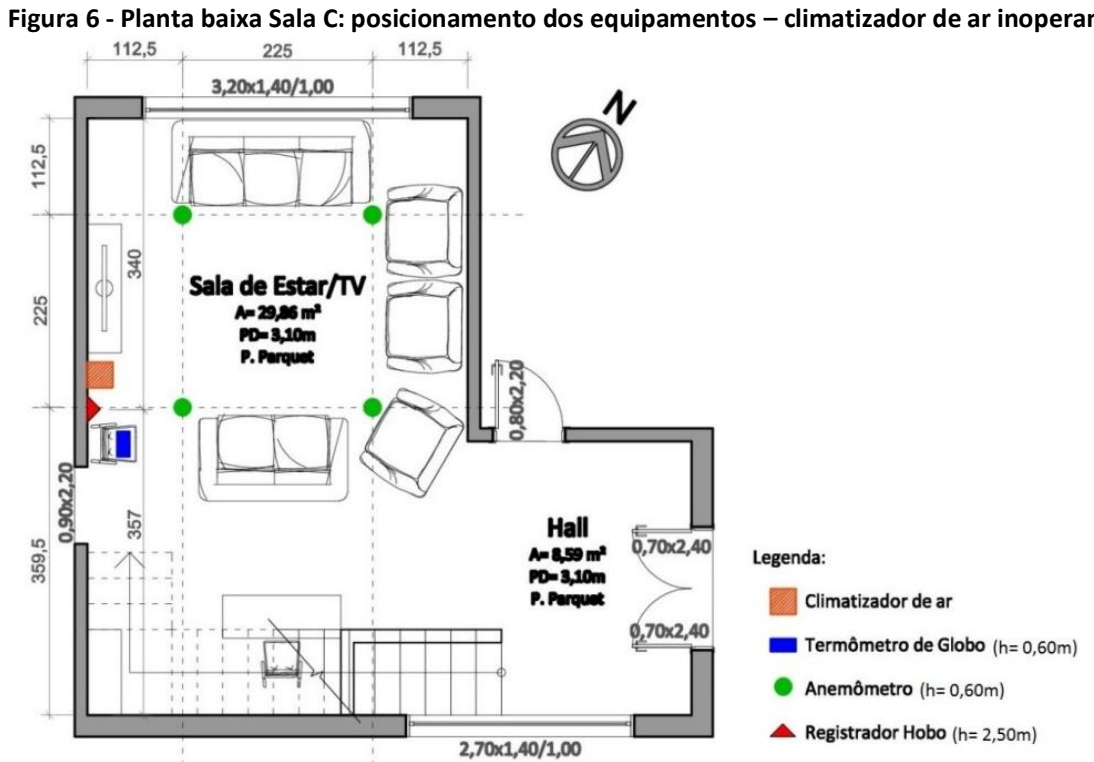

Fonte: Ruviaro (2018). 
Para o termômetro de globo, a localização no centro do ambiente foi evitada, embora seja o que a norma sugere, pois, principalmente nas salas do Lar das Vovozinhas, havia grande fluxo de idosas e funcionárias para alimentação, medicação e banho, o que dificultaria a estabilização do medidor e o deixaria exposto a possíveis acidentes. Conforme a ISO 7726 (ISO, 1998), a temperatura de globo foi medida na altura de 0,60 $\mathrm{m}$, tomando como referência a altura da esfera do equipamento. A leitura da temperatura de globo foi feita após 20 minutos, para estabilização do instrumento. Embora o termômetro de globo tenha sido locado próximo à parede, a influência da proximidade da parede foi considerada insignificante, pois no Lar das Vovozinhas nenhuma das salas é voltada diretamente ao ambiente externo, nem incide radiação solar direta e os ambientes circundantes apresentavam as mesmas condições térmicas. No Longevità, a situação é similar, pois na janela onde incidiria radiação solar direta durante a tarde, não acontecia devido ao afastamento de apenas 1,50 $\mathrm{m}$ da edificação vizinha de dois pavimentos. Assim, a medição realizada neste único ponto foi considerada representativa do ambiente, já que nenhuma das fachadas recebia radiação solar direta.

Os anemômetros foram localizados em 4 a 6 pontos das salas, conforme sua área, posicionados nos locais mais adequados e próximos das participantes, na altura de 0,60 m do piso, equivalente ao nível do abdômen de uma pessoa sentada (ISO 7726, 1998), observando-se que a velocidade do ar variava em função das correntes de ar vindas das aberturas e ventiladores. Aguardou-se a medição estabilizar. Como a velocidade do ar não é medida por equipamento fixo durante o turno de medição e as leituras foram feitas rapidamente, a medição dessa variável não causou grandes transtornos na rotina dos usuários.

A temperatura e umidade relativa do ar foram medidas pelos registradores instalados nos ambientes 15 dias antes do início das medições, registrando dados de 15 em 15 minutos, de agosto a dezembro de 2017, a fim de identificar ondas de frio ou de calor e evitar que as entrevistas fossem realizadas nesses períodos. Por norma, os registradores deveriam ser instalados na altura de $0,60 \mathrm{~m}$ para medir a condição mais próxima da idosa sentada, contudo, não foi possível a instalação nessa altura no Lar das Vovozinhas, pois as idosas arrancariam ou mexeriam no equipamento, conforme alertado pelas cuidadoras. Portanto, foram instalados fora do alcance das idosas, na altura de $2,50 \mathrm{~m}$, fixados nas vigas, em posições centrais dos ambientes. $O$ pé direito da sala de estar A é de 3,00 m, da sala de estar B é de 2,60 m, e da sala de estar Cé 3,10 $\mathrm{m}$, possibilitando a instalação na mesma altura nos ambientes. No Longevità, era possível a instalação do equipamento na altura indicada por norma, entretanto, para comparar os resultados, optou-se por manter as mesmas condições nas três salas de estar.

Para verificar se as medições de temperatura e umidade relativa do ar variavam devido à diferença de altura de $0,60 \mathrm{~m}$, indicado na norma, para 2,50 $\mathrm{m}$, utilizada na pesquisa (fora do plano de conforto térmico para o ser humano e que podem ter influência da cobertura), foram realizadas medições teste nas duas alturas, nos três ambientes, à tarde. A temperatura do ar foi maior na altura de $2,50 \mathrm{~m}$ pela maior proximidade com a cobertura e pelas correntes de ventilação circularem mais abaixo, na altura das esquadrias $(2,10 \mathrm{~m})$. Como os valores variaram na casa dos décimos, considera-se que é possível assumir os valores medidos a $2,50 \mathrm{~m}$ com boa aproximação a medidas em $0,60 \mathrm{~m}$ de altura. O programa HOBOware foi utilizado para acessar os dados dos registradores.

Os equipamentos estavam em conformidade com os preceitos da ASHRAE (2017), foram calibrados antes das medições e permitiram a medição das variáveis ambientais 
com precisão, nos limites da ISO 7726 (ISO, 1998), com exceção do anemômetro, que media somente velocidades a partir de $0,8 \mathrm{~m} / \mathrm{s}$, e, em algumas medições, eram perceptíveis correntes de ar com velocidade inferior, que não foram registradas pelo equipamento. Tal fato pode ter influenciado nos valores do PMV já que somente nos dias em que os ventiladores estiveram ligados na sala de estar $B$ a velocidade do ar foi diferente de zero.

Obtenção dos índices de conforto e análise de dados

O PMV expressa a sensação média de um grupo de indivíduos, caso as diferenças entre as sensações térmicas relatadas individualmente não sejam significativas (FANGER, 1970) e é dado segundo uma escala de sensações térmicas, apresentada na Tabela 1, que relaciona a sensação real do indivíduo com uma escala de sete pontos.

Tabela 1 - Escala de sensações térmicas de sete pontos

\begin{tabular}{cc}
\hline Valor da escala & Sensação térmica \\
\hline+3 & Muito quente \\
\hline+2 & Quente \\
\hline+1 & Levemente quente \\
\hline 0 & Neutro \\
\hline-1 & Levemente frio \\
\hline-2 & Frio \\
\hline-3 & Muito frio \\
\hline
\end{tabular}

Fonte: ISO 7730 (ISO, 2005)

A utilização do modelo é recomendada somente para valores entre -2 e +2 na escala de sensação térmica, e quando os parâmetros principais estão dentro dos seguintes intervalos: taxa metabólica entre 46 e $232 \mathrm{~W} / \mathrm{m}^{2}$ ( 0,8 a 4 met); vestimenta entre 0 $\mathrm{m}^{2} .{ }^{\circ} \mathrm{C} / \mathrm{W}$ e $0,310 \mathrm{~m}^{2} .{ }^{\circ} \mathrm{C} / \mathrm{W}$ (o a $2 \mathrm{clo}$ ); temperatura do ar entre 10 e $30^{\circ} \mathrm{C}$; velocidade do ar entre o e $1 \mathrm{~m} / \mathrm{s}$; e pressão parcial de vapor d'água entre o e $2.700 \mathrm{~Pa}$ (ISO, 2005). Os votos individuais costumam estar distribuídos em torno do valor médio e sempre haverá usuários insatisfeitos com o ambiente térmico.

O PMV foi calculado com o CBE Thermal Comfort Tool, disponível no site da Universidade de Berkeley (HOYT et al., 2017), nos padrões da ASHRAE Standard 55 (ASHRAE, 2017). Foi calculada também a extensão do PMV para climas quentes (FANGER; TOFTUM, 2002) adotando os fatores expectativa alta $(0,5)$, moderada $(0,7)$ e baixa $(0,9)$. A Tabela 2 apresenta a descrição dos fatores expectativa para edificações não condicionadas artificialmente em climas quentes.

Tabela 2 - Fator expectativa para edificações não condicionadas artificialmente em climas quentes

\begin{tabular}{llll}
\multirow{2}{*}{ Expectativa } & \multicolumn{2}{l}{ Classificação de edificações não condicionadas artificialmente } & Períodos quentes \\
\cline { 2 - 3 } Alta & $\begin{array}{l}\text { Localização } \\
\text { com regiões onde edifícios com ar condicionado são }\end{array}$ & Ocorrendo brevemente durante a estação de verão & \multirow{2}{*}{$0,9-1,0$} \\
\hline Moderada & Em regiões com alguns edifícios com ar condicionado & Ocorrendo durante a estação de verão & $0,7-0,9$ \\
\hline Baixa & Em regiões com poucos edifícios com ar condicionado & Ocorrendo durante todas as estações & $0,5-0,7$ \\
\hline
\end{tabular}

Fonte: adaptado de Fanger e Toftum (2002).

A análise de dados relacionou os resultados obtidos em campo e os índices calculados. O PMV e o PMVe foram relacionados com a sensação real dos usuários, levantada por meio dos questionários, para verificar a relação mútua estabelecida entre estes índices e evidenciar o quanto o modelo é explicativo ou não dos dados levantados.

\section{Resultados e discussão}

Os resultados médios de cada dia da pesquisa de campo nas salas de estar A, B e C, são apresentados nas Tabelas 3, 4 e 5, respectivamente. As indicações referem-se à 
RUVIARO, R. S.; ZAMBONATO, B.; GRIGOLETTI, G. de C.

Extensão do PMV para avaliação do conforto térmico de idosas em ambientes com ventilação natural

medição, data de ocorrência, taxa metabólica calculada pelas características antropométricas individuais das idosas (TMT), vestimenta (Roupas), temperatura do ar ( $\mathrm{Ta}$ ), velocidade do ar (Va), temperatura média radiante ( $\mathrm{Tmr}$ ), umidade relativa do ar (UR), sensação térmica relatada (Sens.), preferência térmica (Pref.), voto médio estimado (PMV) e desvio (Des.), que representa a diferença entre o PMV e a sensação térmica relatada.

Como esperado, a taxa metabólica das idosas permaneceu abaixo de 1 met com médias por medição variando entre 0,75 e 0,86 met, como encontrado por Tsuzuki e Ohfuku (2002) que indica que o valor pode chegar a $70 \%$ do valor para jovens adultos. Esta redução pode levar à preferência por ambientes mais aquecidos, devido à dificuldade em aquecer o corpo. Esta variável não apresentou grande influência no posicionamento dos pontos de correlação entre o PMV e a sensação térmica real nos três ambientes. Um exemplo é que na sala de estar $C$, um dos pontos de menor desvio (medição 26) e outro de pior desvio (medição 20) apresentaram a mesma média da TMT (0,78 met).

Tabela 3 - Valores médios dos resultados obtidos por medição na sala de estar A

\begin{tabular}{|c|c|c|c|c|c|c|c|c|c|c|c|}
\hline \multirow{2}{*}{$\begin{array}{l}\text { Mediç } \\
\text { ão }\end{array}$} & \multirow[b]{2}{*}{ Data } & \multirow{2}{*}{$\frac{\text { TMT }}{\text { (met) }}$} & \multirow{2}{*}{$\begin{array}{c}\text { Roupas } \\
\text { (clo) }\end{array}$} & \multirow{2}{*}{$\begin{array}{c}\mathrm{Ta} \\
\left({ }^{\circ} \mathrm{C}\right)\end{array}$} & \multirow{2}{*}{$\frac{V a}{(\mathrm{~m} / \mathrm{s})}$} & \multirow{2}{*}{$\begin{array}{l}\mathrm{Tmr} \\
\left({ }^{\circ} \mathrm{C}\right)\end{array}$} & \multirow{2}{*}{$\begin{array}{l}\text { UR } \\
\text { (\%) }\end{array}$} & \multirow{2}{*}{ Sens. } & \multirow{2}{*}{ Pref. } & \multirow[b]{2}{*}{ PMV } & \multirow[b]{2}{*}{ Des } \\
\hline & & & & & & & & & & & \\
\hline 1 & 28/ago & 0,82 & 1,21 & 24,15 & 0 & 23,85 & 78,94 & 0,14 & $-0,29$ & $-0,03$ & 0,17 \\
\hline 3 & 04/set & 0,80 & 0,98 & 27,67 & 0 & 27,50 & 56,65 & 0,91 & $-0,36$ & 0,63 & 0,28 \\
\hline 6 & $18 /$ set & 0,78 & 1,46 & 21,05 & 0 & 21,63 & 69,32 & $-0,33$ & 0,33 & $-0,83$ & 0,50 \\
\hline 9 & $25 /$ set & 0,79 & 1,13 & 23,32 & 0 & 23,85 & 82,95 & $-0,13$ & 0,13 & $-0,44$ & 0,31 \\
\hline 12 & 02/out & 0,80 & 1,13 & 21,87 & 0 & 22,40 & 48,76 & $-0,40$ & 0,40 & $-1,20$ & 0,80 \\
\hline 16 & 23/out & 0,80 & 1,24 & 22,36 & 0 & 20,97 & 39,04 & $-0,40$ & 0,53 & $-1,19$ & 0,79 \\
\hline 18 & 06/nov & 0,80 & 1,22 & 24,21 & 0 & 24,49 & 49,49 & $-0,07$ & 0,07 & $-0,28$ & 0,22 \\
\hline 21 & $20 /$ nov & 0,78 & 0,98 & 26,31 & 0 & 25,80 & 38,81 & 0,13 & $-0,06$ & $-0,24$ & 0,36 \\
\hline 24 & 11/dez & 0,77 & 0,75 & 27,49 & 0 & 28,37 & 34,95 & 0,30 & $-0,20$ & $-0,02$ & 0,32 \\
\hline
\end{tabular}

Fonte: adaptado de Ruviaro (2018).

Tabela 4 - Valores médios dos resultados obtidos por medição na sala de estar B

\begin{tabular}{|c|c|c|c|c|c|c|c|c|c|c|c|}
\hline \multirow{2}{*}{ Medição } & \multirow{2}{*}{ Data } & \multirow{2}{*}{$\begin{array}{c}\text { TMT } \\
\text { (met) }\end{array}$} & \multirow{2}{*}{$\begin{array}{c}\text { Roupas } \\
\text { (clo) }\end{array}$} & \multirow{2}{*}{$\begin{array}{c}\mathrm{Ta} \\
\left({ }^{\circ} \mathrm{C}\right)\end{array}$} & \multirow{2}{*}{$\frac{V a}{(m / s)}$} & \multirow{2}{*}{$\begin{array}{l}\mathrm{Tmr} \\
\left({ }^{\circ} \mathrm{C}\right)\end{array}$} & \multirow{2}{*}{$\begin{array}{l}\text { UR } \\
(\%)\end{array}$} & \multirow{2}{*}{ Sens. } & \multirow{2}{*}{ Pref. } & \multirow[b]{2}{*}{ PMV } & \multirow[b]{2}{*}{ Des } \\
\hline & & & & & & & & & & & \\
\hline 2 & 28/ago & 0,82 & 0,96 & 25,47 & 0,10 & 25,73 & 79,86 & 0,67 & $-0,11$ & 0,02 & 0,64 \\
\hline 4 & 04/set & 0,77 & 0,84 & 30,44 & 0,36 & 28,74 & 50,48 & 1,00 & $-0,40$ & 0,78 & 0,22 \\
\hline 7 & $18 /$ set & 0,80 & 1,28 & 22,36 & 0 & 21,33 & 64,07 & 0,00 & 0,29 & $-0,79$ & 0,79 \\
\hline 10 & $25 /$ set & 0,79 & 1,01 & 25,80 & 0 & 24,60 & 75,21 & 0,44 & $-0,33$ & $-0,04$ & 0,48 \\
\hline 13 & 02/out & 0,78 & 1,21 & 21,78 & 0 & 22,07 & 53,18 & $-0,40$ & 0,80 & $-1,19$ & 0,79 \\
\hline 17 & 23/out & 0,79 & 1,23 & 26,63 & 0 & 22,60 & 33,75 & 0,00 & 0,17 & $-0,84$ & 0,84 \\
\hline 19 & $06 /$ nov & 0,81 & 1,01 & 24,04 & 0 & 25,45 & 49,83 & 0,00 & 0,33 & $-0,47$ & 0,47 \\
\hline 22 & $20 /$ nov & 0,80 & 0,83 & 26,34 & 0,82 & 31,03 & 35,41 & 0,17 & 0,17 & $-0,74$ & 0,90 \\
\hline 25 & 11/dez & 0,80 & 0,76 & 29,96 & 0,20 & 28,29 & 28,73 & 0,63 & $-0,38$ & 0,44 & 0,19 \\
\hline
\end{tabular}

Fonte: adaptado de Ruviaro (2018).

\begin{tabular}{|c|c|c|c|c|c|c|c|c|c|c|c|}
\hline \multirow{2}{*}{ Medição } & \multirow{2}{*}{ Data } & \multirow{2}{*}{$\begin{array}{c}\text { TMT } \\
\text { (met) }\end{array}$} & \multirow{2}{*}{$\begin{array}{c}\text { Roupas } \\
\text { (clo) }\end{array}$} & \multirow{2}{*}{$\begin{array}{c}\mathrm{Ta} \\
\left({ }^{\circ} \mathrm{C}\right)\end{array}$} & \multirow{2}{*}{$\frac{V a}{(\mathrm{~m} / \mathrm{s})}$} & \multirow{2}{*}{$\begin{array}{l}\mathrm{Tmr} \\
\left({ }^{\circ} \mathrm{C}\right)\end{array}$} & \multirow{2}{*}{$\begin{array}{l}\text { UR } \\
\text { (\%) }\end{array}$} & \multirow{2}{*}{ Sens. } & \multirow{2}{*}{ Pref. } & \multirow{2}{*}{ PMV } & \multirow{2}{*}{ Des } \\
\hline & & & & & & & & & & & \\
\hline 5 & 06/set & 0,86 & 1,16 & 22,55 & 0 & 22,27 & 70,13 & 0,33 & $-0,33$ & $-0,45$ & 0,78 \\
\hline 8 & $19 /$ set & 0,80 & 1,52 & 21,88 & 0 & 21,80 & 78,12 & $-0,25$ & 0,25 & $-0,51$ & 0,26 \\
\hline 11 & $26 /$ set & 0,77 & 0,86 & 25,91 & 0 & 25,80 & 73,99 & 0,25 & $-0,25$ & $-0,25$ & 0,50 \\
\hline 14 & 03/out & 0,77 & 1,03 & 22,21 & 0 & 22,20 & 41,01 & 0,00 & 0,00 & $-1,64$ & 1,64 \\
\hline 15 & 16/out & 0,77 & 1,37 & 22,75 & 0 & 23,05 & 70,61 & 0,25 & $-0,25$ & $-0,55$ & 0,80 \\
\hline 20 & $10 /$ nov & 0,78 & 0,96 & 25,66 & 0 & 24,90 & 50,82 & 1,25 & $-0,75$ & $-0,46$ & 1,71 \\
\hline 23 & 04/dez & 0,75 & 1,03 & 24,32 & 0 & 23,25 & 73,48 & $-0,33$ & 0,00 & $-0,08$ & $-0,25$ \\
\hline 26 & 15/dez & 0,78 & 0,57 & 29,85 & 0 & 31,20 & 47,32 & 1,50 & $-0,75$ & 1,14 & 0,36 \\
\hline
\end{tabular}

Fonte: adaptado de Ruviaro (2018).

Entretanto, quando se compara o público pesquisado com a mesma faixa etária do sexo masculino, observa-se que a equação de MIFFLIN et al. (1990) prevê um aumento de $11,23 \%$ na TMT considerando as mesmas características de peso, idade e altura, 
alterando somente o sexo. Este aumento aproxima a taxa metabólica de homens idosos do valor de 1 met indicado pela ISO 7730 (ISO, 2005) para atividade estacionária no cálculo do PMV, o que poderia resultar em melhor correlação entre PMV e sensação térmica real, indicando que o gênero pode ter influência no cálculo do PMV. Sugere-se a aplicação deste método em idosos homens e população mista idosa para viabilizar a comparação de resultados. No estudo de Panet, Araújo e Araújo (2020), aplicado a ambos os sexos, constatou-se que as mulheres sentem mais calor e os homens mais frio, observando que, além do metabolismo, a sensação térmica real também varia conforme o gênero.

O nível médio de vestimenta das idosas variou entre 0,57 clo e 1,52 clo, com média de 1,07 clo, valores elevados se comparados com a média de 0,32 para a população feminina avaliada por Panet, Araújo e Araújo (2020), visto que as temperaturas registradas durante os levantamentos em Santa Maria são próximas às normais climatológicas da área de estudo dos autores. Esta diferença entre as regiões pode ter relação com aclimatação, histórico térmico e expectativa, uma vez que as idosas residentes em Santa Maria esperavam temperaturas menores no período de transição entre o inverno e a primavera, que não aconteceram no ano atípico em que ocorreram as medições.

\section{Sensação Térmica e PMV}

A Figura 7 apresenta a correlação da sensação térmica relatada com o PMV, considerando os valores médios das 26 medições indicadas em legenda por sala de estar. A reta representa a perfeita correlação entre as variáveis PMV e sensação térmica real. Os pontos acima da reta indicam que os indivíduos relatam sentir mais calor do que o modelo prevê, e os pontos abaixo da reta indicam que os indivíduos relatam sentir mais frio.

Os valores de sensação térmica médios são, em sua maioria, localizados acima da reta. Dos 26 pontos, 25 foram plotados acima da reta (96,15\%), e 1 ponto está localizado abaixo da linha (3,85\%). Os valores de sensação térmica relatada (de -0,4 a 1,5) foram superiores ao PMV calculado (de -1,64 a 1,14) para a maioria das medições, com desvio médio de 0,57 pontos, o que aponta que as idosas relataram se sentir mais aquecidas do que o modelo estima, visto que o PMV superestimou a sensação de frio das idosas. Hughes e Natarajan (2019) também observaram resultados de PMV menores que a sensação térmica relatada por idosos em residências ventiladas naturalmente em Bath, no Reino Unido, em um verão típico com temperatura média interna de $15,5^{\circ} \mathrm{C}$ e um verão atípico com $17,1^{\circ} \mathrm{C}$, e em inverno com temperatura média interna de 18,9 e $18,7^{\circ} \mathrm{C}$ (HUGHES et al., 2019). As diferenças encontradas entre a sensação térmica relatada e o PMV podem estar relacionadas à taxa metabólica, que esteve abaixo da faixa de 0,8 a 4 met em 14 das 26 medições, à aclimatação, à expectativa das idosas em relação às condições ambientais e ao fato dos ambientes analisados serem ventilados naturalmente, onde o PMV é conhecido por ter menor aplicabilidade. 
Figura 7 - Gráfico de correlação dos valores médios do PMV e as sensações térmicas médias

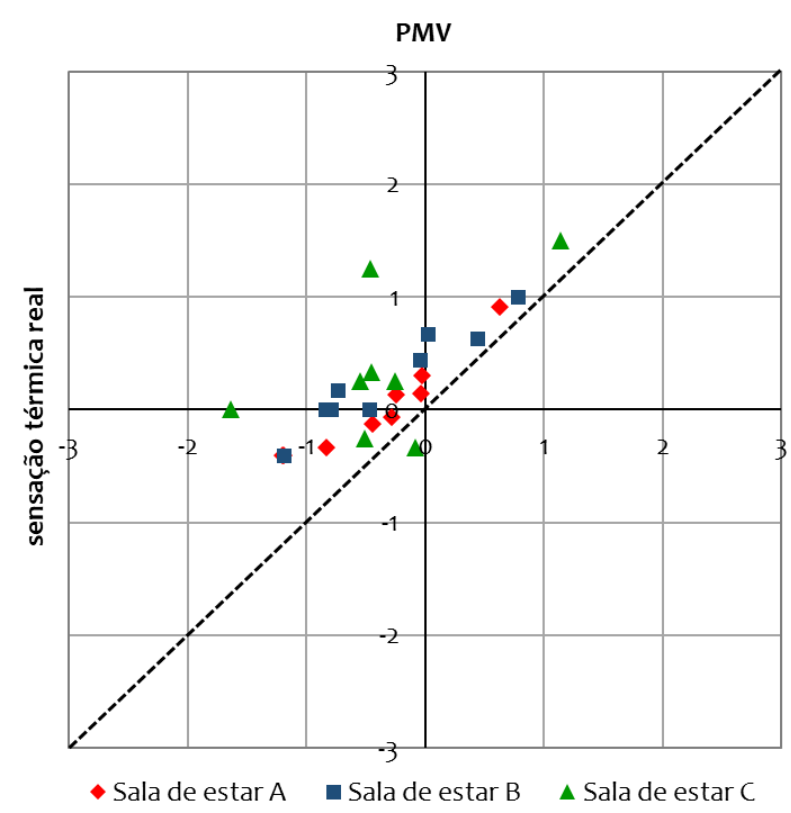

Fonte: adaptado de Ruviaro, Grigoletti e Zambonato (2019).

A sensação térmica e o PMV apresentaram um coeficiente de correlação $(r)$ igual a 0,7480 e um coeficiente de adequabilidade ou determinação $\left(R^{2}\right)$ igual a 0,5595, indicando que $55,95 \%$ das variações das sensações térmicas relatadas são explicadas pelo modelo PMV. Considera-se a porcentagem explicada pelo modelo PMV elevada, tendo em vista a comparação de dados obtidos em campo em condições ambientais variáveis com um modelo desenvolvido em laboratório e fatores físicos ambientais controlados e homogêneos. Entretanto, não há uma distribuição homogênea dos pontos médios no gráfico em relação à reta. Conclui-se, portanto, que o modelo PMV não se aplica à população e ambientes estudados.

A análise de correlação das salas separadamente indica que as salas A e B apresentam respectivamente correlação $(r)$ de 0,9524 e 0,9578 e adequabilidade $\left(R^{2}\right)$ de 0,9071 e 0,9174 , enquanto a sala $C$ apresenta $r$ de 0,5621 e $R^{2}$ de 0,3159. Observa-se também que os pontos mais afastados da reta são devido às medições na sala de estar $C$, o que pode ser justificado pela situação social e expectativa das idosas, tendo em vista que este ambiente pertence a um residencial geriátrico particular, onde, em sua maioria, as idosas foram tiradas de um ambiente familiar com maior conforto, o que influencia sua percepção ambiental. Já as idosas do Lar das Vovozinhas saíram de uma condição ambiental mais precária do que o residencial, em que, mesmo em dias com temperaturas elevadas, as idosas relatavam estar confortáveis nas Salas de estar A e B. Em aspectos físicos, o Longevità apresenta um ambiente mais estruturado e aconchegante, sala de estar com menor área e menor número de idosas, o que pode interferir nas análises estatísticas. Os três ambientes possuem as janelas voltadas a noroeste, indicando que o maior desconforto na sala de estar $C$ pode não ter influência da orientação solar.

A sala de estar $A$ apresentou pontos mais próximos da reta de referência do que a sala de estar B. Acredita-se que essa diferença seja devido à ventilação natural na sala de estar $A$ e à localização no térreo, mais afastada da cobertura e com condições ambientais mais confortáveis. A sala de estar $B$, que possui os pontos mais afastados da reta comparando-se com a sala de estar A, evidencia que as idosas relatavam se sentir mais aquecidas do que o modelo prevê. Esta possui ventilação indireta 
RUVIARO, R. S.; ZAMBONATO, B.; GRIGOLETTI, G. de C.

Extensão do PMV para avaliação do conforto térmico de idosas em ambientes com ventilação natural

permanente e localiza-se no segundo pavimento, com cobertura em laje de concreto e telha de zinco, sendo o ambiente que esteve com ventiladores ligados em quatro medições, operados por funcionários do residencial de acordo com a demanda das idosas, indicando a sua insatisfação com o ambiente térmico.

\section{Extensão do PMV}

O fator expectativa (e) no índice PMV foi aplicado para verificar sua influência na correlação do índice com as sensações térmicas relatadas pelas idosas e possível aplicação do modelo PMV no público estudado. As Figuras 8 , 9 e 10 apresentam a correlação do PMVe com a sensação térmica relatada, para verificar qual seria o mais indicado para corrigir as diferenças entre o PMV obtido em campo e o PMV calculado.

Figura 8 - Correlação entre sensações térmicas relatadas e PMV corrigido por e=0,5

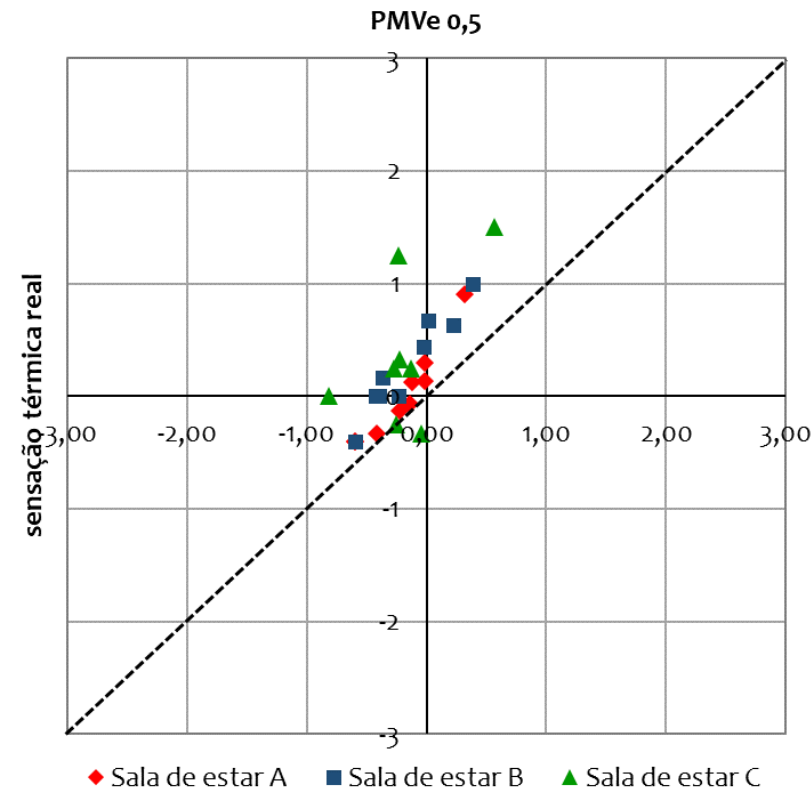

Fonte: as autoras.

Figura 9 - Correlação entre sensações térmicas relatadas e PMV corrigido por e=0,7

PMVe 0,7

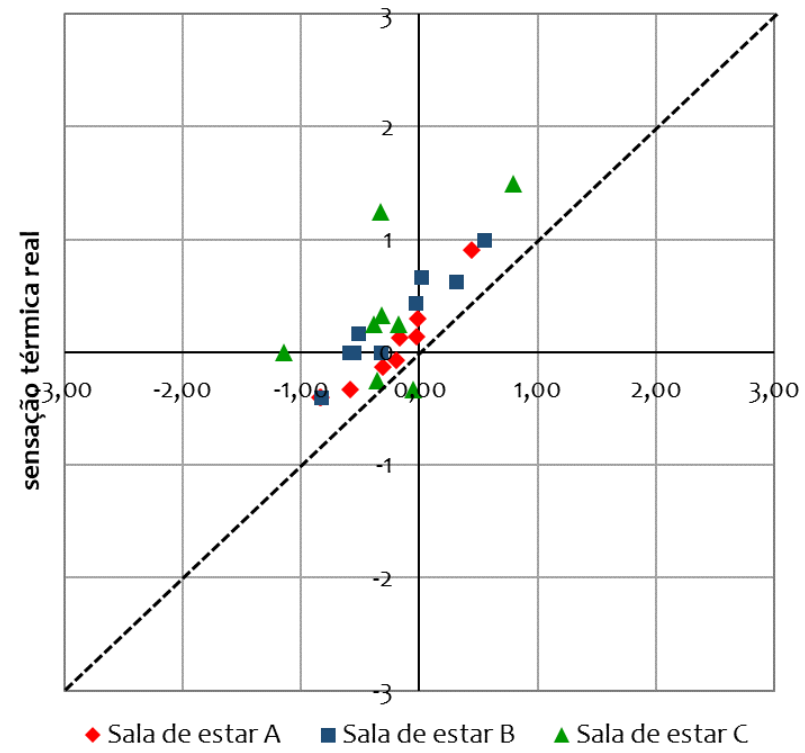

Fonte: as autoras. 


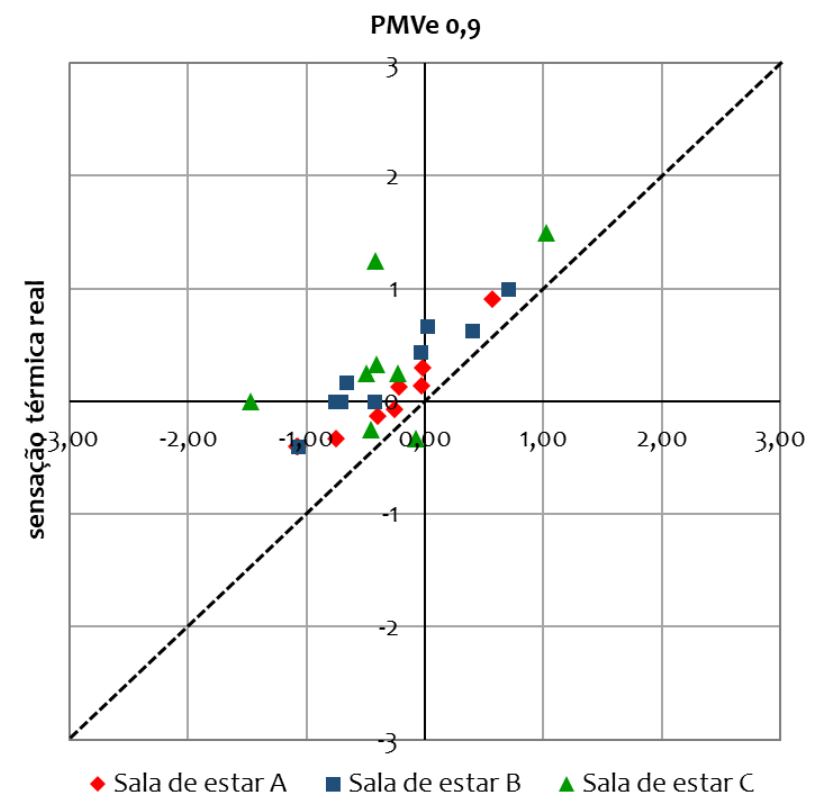

Fonte: as autoras.

Para a maioria das medições (21 medições, 80,77\%), o uso do fator expectativa aproximou os valores do PMVe da sensação térmica, uma vez que os valores do PMV eram mais baixos que a sensação térmica e a multiplicação dos fatores menores que 1 resulta em valores menores.

Com a aplicação do fator expectativa, considerando a correlação linear entre sensação térmica e PMV, o coeficiente de correlação $(r)$ e o coeficiente de adequabilidade ou determinação $\left(R^{2}\right)$ entre as variáveis mantêm-se os mesmos. O PMVe de 0,5 apresentou maior número de pontos sobre a reta (3 pontos, 11,54\%), assim como distribuiu os demais pontos equilibradamente e próximos da reta de referência do gráfico. Embora os pontos estejam mais unidos e próximos da reta de referência, continuam localizados, em sua maioria, acima da reta, indicando que ainda assim, o PMVe resulta em valores menores que a sensação térmica relatada. $O$ desvio médio entre PMV e sensação térmica passou de 0,57 para 0,40 entre o PMVe de 0,5 e a sensação térmica relatada, aproximando, portanto, os dados levantados do modelo para 21 das 26 medições $(80,77 \%)$.

O PMVe de 0,7 e o PMVe de 0,9, correlacionados com a sensação térmica real das idosas, não possuem nenhum ponto sobre a reta de referência. Quando aplicado o fator expectativa de 0,7 , os desvios médios foram de 0,47 e 0,54, ainda abaixo do desvio médio entre PMV e sensação térmica. No entanto, o PMV $e_{0,7}$ e $P M V e_{0,9}$ ainda são mais distantes da sensação térmica dos valores de $P M V e_{0,5}$.

Comparando os três valores de PMVe, é possível estimar que, quanto menor o fator expectativa, menor é a diferença entre PMVe e sensação térmica para valores negativos (frio). Na amostra, apenas cinco medições (19,23\%) (medições 2, 3, 4, 25 e 26) apresentaram menor desvio médio para o PMV do que para os valores de PMVe. Nestas medições, a sensação térmica estava acima de 0,5 ponto e, ainda assim, acima dos valores de PMVe.

Conclui-se que a extensão do PMV não corrige as imprecisões do modelo, mas reduz as diferenças encontradas com os valores de sensação térmica relatada, diminuindo a superestimação da sensação de frio que o PMV resultou para idosas em atividade 
estacionária ocupando salas de estar ventiladas naturalmente. Resultado similar foi encontrado por Sousa (2018), com amostra de adultos com diferentes históricos térmicos no semiárido paraibano.

De acordo com pesquisadores (NICOL; HUMPHREYS, 2002), as diferenças encontradas entre o modelo PMV e a aplicação no cotidiano das pessoas podem ser devido a erros sistemáticos. Também devem ser consideradas as imprecisões na estimação da taxa metabólica e do isolamento das vestimentas, assim como as possíveis influências psicológicas no ambiente estudado, que podem afetar as respostas dos ocupantes para o ambiente térmico. Van Hoof e Hensen (2006) concluíram que o modelo PMV não é o mais preciso para a população idosa, mas ainda é o mais indicado.

Na presente pesquisa, não foi considerada a taxa metabólica da ISO 7730 (ISO, 2005) e sim a calculada em função das características antropométricas de cada idosa. Entretanto, embora os valores calculados estimem com maior exatidão a taxa metabólica, a aplicação do modelo PMV é indicada para a faixa de 0,8 a 4 met (46 a 232 $\mathrm{W} / \mathrm{m}^{2}$ ), e diversas idosas tiveram suas taxas metabólicas inferiores a este parâmetro, observando que a menor atividade metabólica calculada foi de $40 \mathrm{~W} / \mathrm{m}^{2}$.

O isolamento térmico da vestimenta neste estudo não implicou em uma variável com imprecisões, pois as idosas utilizavam vestimentas convencionais. Além disso, considerou-se a influência do mobiliário. A aplicação do modelo PMV é indicada para a faixa de 0 a 2 clo e a maioria das idosas se enquadraram neste parâmetro, exceto uma que ultrapassou este limite, atingindo 2,24 clo sentada em uma poltrona com cobertor.

A faixa de temperatura do ar esteve entre $10{ }^{\circ} \mathrm{C}$ a $30{ }^{\circ} \mathrm{C}$ e a velocidade do ar se concentrou na faixa de o a $1 \mathrm{~m} / \mathrm{s}$. De 44,05\% dos dados que não se explicam pelo modelo PMV, a imprecisão na velocidade do ar pode ter sido um limitador da pesquisa. Às vezes, na sala $C$, havia uma leve corrente de ar, porém o equipamento não registrava. As limitações para instalação dos equipamentos de medição de temperatura do ar, umidade do ar e temperatura de globo no local indicado, devido ao funcionamento das salas de estar, também podem ter apresentado alguma influência nos resultados.

No ano de 2017 não foram registradas temperaturas muito baixas no inverno, podendo justificar a sensação das idosas sentirem mais calor, já que esperavam frio naquela situação. De acordo com os dados históricos do Instituto Nacional de Meteorologia (INMET, 2019), nos meses de julho a setembro de 2017, a média da temperatura compensada em Santa Maria foi de $17,56{ }^{\circ} \mathrm{C}$ e, comparando-se com o ano anterior de 2016, nos mesmos meses, a média da temperatura compensada foi de $14,91{ }^{\circ} \mathrm{C}$. Considerando os meses de agosto e setembro, a temperatura mínima média ocorreu em agosto de $2017 \mathrm{com} 12,07^{\circ} \mathrm{C}$. No ano de 2016, a temperatura mínima média ocorreu mais tarde, no mês de setembro, e foi de $10,42{ }^{\circ} \mathrm{C}$. Salienta-se também que a temperatura do ar nas medições de agosto de 2017 variou entre $24{ }^{\circ} \mathrm{C}$ e $25^{\circ} \mathrm{C}$, já no início do mês de setembro variou entre $27{ }^{\circ} \mathrm{C}$ a $30{ }^{\circ} \mathrm{C}$, atípicas no inverno de Santa Maria. Nicol e Humphreys (2002) relatam que a aclimatação fisiológica também afeta a tolerância das pessoas a uma condição térmica que difere da preferida: mesmo em dias com temperaturas elevadas, as idosas do Lar das Vovozinhas ainda relatavam estar confortáveis, já as idosas do Longevità demonstravam maior insatisfação com o ambiente térmico.

Embora a distribuição dos pontos médios aponta a tendência de as idosas sentirem-se mais aquecidas, espera-se que os idosos sintam mais frio do que adultos, justamente porque há a redução da atividade metabólica. Entretanto, acredita-se que o resultado obtido pode ser justificado pela maior tolerância em relação ao frio das idosas, 
decorrentes das experiências de vida, já que a maioria dos resultados se deu em função dos ambientes do Lar das Vovozinhas.

\section{Conclusão}

Esta pesquisa analisou se o modelo PMV e a extensão do modelo PMVe podem ser aplicados na avaliação do conforto térmico de idosas que ocupam salas de estar ventiladas naturalmente em dois residenciais geriátricos em região de clima temperado com verão quente ( $\mathrm{Cfa}$ ). Na aplicação do modelo, a correlação das sensações relatadas pelas idosas com o PMV indicou que 55,95\% das sensações térmicas reais foram explicadas pelo modelo PMV, porcentagem considerada elevada. Entretanto, verificou-se que não houve uma distribuição homogênea dos pontos médios no gráfico de correlação entre as variáveis. Entre os pontos médios, 96,15\% ficaram acima da reta, indicando que as idosas se sentiam mais aquecidas do que o modelo prevê, diferença média de 0,57 pontos. A fim de corrigir as imprecisões do modelo, foi aplicada a extensão do PMV. O PMV $e_{0,5}$ apresentou menor desvio médio $(0,40)$ entre PMV e sensação térmica, resultando em valores mais próximos da sensação térmica de idosas, especialmente para medições em que a sensação era negativa ou abaixo de 0,5 . Os fatores expectativa 0,7 e 0,9 resultaram em desvios médios maiores ( 0,47 e 0,54 , respectivamente), ainda que menores do que os resultados do PMV. A extensão do PMV, portanto, não corrige, mas aproxima os valores de sensação térmica estimada e PMV para a população estudada. A variável taxa metabólica teve grande influência nos resultados, bem como o gênero estudado. Sugere-se, para trabalhos futuros, a aplicação do método em idosos homens a fim de verificar se há maior correlação entre sensação relatada e sensação calculada através dos modelos do PMV com este público, visto que o metabolismo do sexo masculino é mais elevado que o de mulheres, elevando a faixa da taxa metabólica para os níveis entre 0,8 e 4 met, para qual o PMV é indicado.

\section{Agradecimentos}

O presente trabalho foi realizado com o apoio do Programa de Demanda Social da Coordenação de Aperfeiçoamento de Pessoal de Nível Superior (CAPES), nível mestrado, junto a Universidade Federal de Santa Maria e com apoio do Programa Institucional de Bolsas de Iniciação Científica PIBIC do Conselho Nacional de Desenvolvimento Científico e Tecnológico (CNPq) com Registro no Portal de Projetos da UFSM n.045856.

\section{Notas}

Este artigo é uma versão estendida do artigo "APLICAÇÃO DO MODELO DE FANGER NA AVALIAÇÃO DO CONFORTO TÉRMICO DA POPULAÇÃO IDOSA FEMININA" (RUVIARO; GRIGOLETTI; ZAMBONTTO, 2019) apresentados pelos autores no XV ENCONTRO NACIONAL DE CONFORTO NO AMBIENTE CONSTRUÍDO \& XI ENCONTRO LATINOAMERICANO DE CONFORTO NO AMBIENTE CONSTRUÍDO.

\section{Referências}

ABNT - Associação Brasileira de Normas Técnicas. NBR 15220-3: Desempenho térmico de edificações - Parte 3: Zoneamento bioclimático brasileiro e estratégias de condicionamento térmico passivo para habitações de interesse social. Rio de Janeiro, 2005.

ABOUBAKRI, O. et al. Thermal comfort and mortality in a dry region of Iran, Kerman; a 12-year time series analysis. Theoretical and Applied Climatology, v. 139, n. 1-2, p. 403-413, 2020. DOI: https://doi.org/10.1007/s00704-019-02977-8 
RUVIARO, R. S.; ZAMBONATO, B.; GRIGOLETTI, G. de C.

Extensão do PMV para avaliação do conforto térmico de idosas em ambientes com ventilação natural

ANDERSON, G. S.; MENEILLY, G. S.; MEKJAVIC, I. B. Passive temperature lability in the elderly. European Journal of Applied Physiology and Occupational Physiology, v. 73, n. 3-4, p. 278-286, 1996. DOI: https://doi.org/10.1007/BF02425488

ASHRAE - AMERICAN SOCIETY OF HEATING, REFRIGERATING AND AIR CONDITIONING ENGINEERS. ASHRAE Handbook Fundamentals: Thermal Comfort. Capítulo 9. Atlanta, 2009.

ASHRAE - AMERICAN SOCIETY OF HEATING, REFRIGERATING AND AIR CONDITIONING ENGINEERS. ASHRAE Standard 55: Thermal Environmental Conditions for Human Occupancy. Atlanta, 2017.

BAQUERO LARRIVA, M. T.; HIGUERAS GARCÍA, E. Thermal comfort for the elderly: A systematic review of the scientific literature. Revista Espanola de Geriatria y Gerontologia, v. 54, n. 5, p. 280-295, 2019. DOI: https://doi.org/10.1016/j.regg.2019.01.006

BONGANHA, V. et al. Predictive Equations Overestimate the Resting Metabolic Rate in Postmenopausal Women. The Journal of Nutrition, Health \& Aging, v. 17, n. 3, p. 211-214, 2013. DOI: https://doi.org/10.1007/s12603-012-0395-3

BRAGER, G. S.; DEAR, R. J. Thermal adaptation in the built environment: A literature review. Energy and Buildings, v. 27, n. 1, p. 83-96, 1998. DOI: https://doi.org/10.1016/S0378-7788(97)00053-4

DEAR, R.; BRAGER, G.; COOPER, D. Developing an Adaptive Model of Thermal Comfort and Preference. Final Report, ASHRAE RP-884, Mar.1997.

FANGER, P. O. Thermal comfort: analysis and applications in environmental engineering. Copenhagen: Danish Technical Press, 1970.

FANGER, P. O.; TOFTUM, J. Extension of the PMV model to non-air-conditioned buildings in warm climates. Energy and buildings, v.34, n. 6, p. 533-536, 2002. DOI: https://doi.org/10.1016/S0378-7788(02)00003-8

GRIEFAHN, B.; KUNEMUND, C. The effects of gender, age, and fatigue on susceptibility to draft discomfort. Journal of Thermal Biology, v. 26, p. 395-400, 2001. DOI: https://doi.org/10.1016/S0306-4565(01)00050-X

GUYTON, A. C.; HALL, J. E. Guyton and Hall Textbook of Medical Physiology. 12. ed. Jackson: Elsevier, 2010.

HAVENITH, G. Temperature regulation and technology. Gerontechnology, v. 1, n. 1, p. 41-49, 2001. DOI: https://doi.org/10.4017/GT.2001.01.01.004.00

HOYT, T. et al. CBE Thermal Comfort Tool. Berkeley: Center for the Built Environment, University of California, 2017. Disponível em: http://cbe.berkeley.edu/comforttool. Acesso em: maio 2018.

HUGHES, C. et al. Winter thermal comfort and health in the elderly. Energy Policy, v. 134, p. 110954, 2019. DOI: https://doi.org/10.1016/j.enpol.2019.110954

HUGHES, C.; NATARAJAN, S. Summer thermal comfort and overheating in the elderly. Department of Architecture and Civil Engineering, University of Bath. Building Services Engineering Research Technology, Bath, v. 40, n. 4, p. 426-445, 2019. DOI: https://doi.org/10.1177/0143624419844518

IBGE - INSTITUTO BRASILEIRO DE GEOGRAFIA E ESTATÍSTICA. Agência de Notícias. Em 2016, expectativa de vida era de 75,8 anos. Dez. 2017. Disponível em: https://agenciadenoticias.ibge.gov.br/agencia-sala-de-imprensa/2013agencia-de-noticias/releases/18470-em-2016-expectativa-de-vida-era-de-75-8-anos.html. Acesso em: fev. 2020.

INMET - INSTITUTO NACIONAL DE METEOROLOGIA. Dados meteorológicos - Histórico de dados meteorológicos. Disponível em: https://portal.inmet.gov.br/dadoshistoricos. Acesso em: jul. 2020.

INMET - INSTITUTO NACIONAL DE METEOROLOGIA. Dados meteorológicos - Mapa de estações meteorológicas. Disponível em: https://mapas.inmet.gov.br/. Acesso em: ago. 2019. 
ISO - INTERNATIONAL ORGANIZATION FOR STANDARDIZATION. ISO 7726: Ergonomics of the thermal environment - Instruments and methods for measuring physical quantities. Geneva International Standards Institution, 1998.

ISO - INTERNATIONAL ORGANIZATION FOR STANDARDIZATION. ISO 7730: Analytical determination and interpretation of thermal comfort using calculation of the PMV and PPD indices and local thermal comfort criteria. Geneva International Standards Institution, 2005.

ISO - INTERNATIONAL ORGANIZATION FOR STANDARDIZATION. ISO 8996: Ergonomics: Determination of metabolic heat production. Genebra, 2004.

KARJALAINEN, S. Gender differences in thermal comfort and use of thermostats in everyday thermal environments. Building and Environment, v. 42, n. 4, p. 1594-1603, 2007. DOI: https://doi.org/10.1016/j.buildenv.2006.01.009

KENEY, W. L.; MUNCE, T. A. Invited Review: aging and human temperature regulation. Journal of Applied Physiology, v. 95, n. 6, p. 2598-2603, 2003. DOI: https://doi.org/10.1152/japplphysiol.00202.2003

KRÜGER, E. L.; ROSSI, F. A. Effect of personal and microclimatic variables on observed thermal sensation from a field study in southern Brazil. Building and Environment, v. 46, n. 3, p. 690-697, 2011. DOI: https://doi.org/10.1016/j.buildenv.2010.09.013

KUINCHTNER, A.; BURIOL, G. A. Clima do estado do Rio Grande do Sul segundo a classificação climática de Koppen e Thornthwaite. Disciplinarum Scientia, Santa Maria, v.2 p. 171-182, 2001. DOI: https://doi.org/10.37779/nt.v2i1.1136

LEYVA, E. W. A.; BEARMAN, A.; DAVIDSON, P. M. Health impact of climate change in older people: an integrative review and implication for nursing. Journal of Nursing Scholarship, v.49, n.6, 2017, p. 670-678. DOI: https://doi.org/10.1111/jnu.12346

MAHAN, L. K.; STUMP, S. E. Krause: Alimentos, Nutrição e Dietoterapia. São Paulo: Editora Roca, 1998.

MENDES, A. et al. The Influence of Thermal Comfort on the Quality of Life of Nursing Home Residents. Journal of Toxicology and Environmental Health, v. 80, n. 13-15, p. 729-739, 2017. DOI:

https://doi.org/10.1080/15287394.2017.1286929

MIFFLIN, M. D. et al. A new predictive equation for resting energy expenditure in healthy individuals. American Journal of Clinical Nutrition, v. 51, n. 2, p. 241-247, 1990. DOI: https://doi.org/10.1093/ajcn/51.2.241

MONTANHEIRO, F. P. Percepção térmica de idosos. 2016. 70 p. Dissertação (Mestrado em Arquitetura e Urbanismo) - Universidade Estadual Paulista, Bauru, 2016.

NAÇÕES UNIDAS. World Population Prospects 2019: Highlights. ST/ESA/SER.A/423. Disponível em: https://population.un.org/wpp/Publications/. Acesso em: jul. 2019.

NICOL, J. F.; HUMPHREYS, M. A. Adaptive thermal comfort and sustainable thermal standards for buildings. Energy and Buildings, v. 34, n. 6, p. 563-572, 2002. DOI: https://doi.org/10.1016/S0378-7788(02)00006-3

PANET, M. F. Um futuro confortável: modelagem preditiva de sensação térmica de pessoas idosas residentes em localidade do semiárido da Paraíba/Brasil. 2018. 168p. Tese (Doutorado em Arquitetura e Urbanismo) Universidade Federal do Rio Grande do Norte, Natal, 2018.

PANET, M. F; ARAÚJO, V. M. D.; ARAÚJO, E. H. S. No calor da idade: parâmetros de conforto térmico para idosos residentes em localidade do semiárido paraibano. Ambiente Construído, Porto Alegre, v. 20, n. 2, p. $135-149,2020$. DOI: https://doi.org/10.1590/s1678-86212020000200392

PARSONS, K. C. The Effects of Gender, Acclimation State, the Opportunity to Adjust Clothing and Physical Disability on Requirements for Thermal Comfort. Energy and Buildings, v. 34, n. 6, p. 593-599, 2002. DOI:

https://doi.org/10.1016/S0378-7788(02)00009-9 
REIDLINGER, D. P.; WILLIS, J. M.; WHELAN, K. Resting metabolic rate and anthropometry in older people: a comparison of measured and calculated values. Journal of Human Nutrition and Dietetics, v. 28, n. 1, p. 72-84, 2015. DOI: https://doi.org/10.1111/jhn.12215

ROSSATO, M. S. Os climas do Rio Grande do Sul: Variabilidade, tendências e tipologia. 2011. 253f. Tese (Doutorado em Geografia) - Universidade Federal do Rio Grande do Sul, Porto Alegre, 2011.

RUVIARO, R. S. Influência da população idosa feminina na avaliação de conforto térmico pelo modelo de Fanger 2018. 18of. Dissertação (Mestrado em Engenharia Civil) - Universidade Federal de Santa Maria, Santa Maria, 2018.

RUVIARO, R.S.; GRIGOLETTI, G. de C; ZAMBONATO, B. Aplicação do modelo de Fanger na avaliação do conforto térmico da população idosa feminina. In: ENCONTRO NACIONAL DE CONFORTO NO AMBIENTE CONSTRUÍDO, 15.; ENCONTRO LATINO-AMERICANO DE CONFORTO NO AMBIENTE CONSTRUÍDO, 11., 2019, João Pessoa. Anais [...]. Porto Alegre: ANTAC, 2019.

SARTORI, M. da G. B. Clima e percepção. 2000. Tese (Doutorado em Geografia) - Universidade de São Paulo, São Paulo, 2000.

SON, J. Y. et al. The impact of temperature on mortality in a subtropical city: effects of cold, heat, and heat waves in São Paulo, Brazil. International Journal of Biometeorology, v. 60, n. 1, p. 113-121, 2016. DOI: https://doi.org/10.1007/s00484-015-1009-7

SOUSA, M. C. B. Desejo por conforto térmico: Estratégias adaptativas e modelos de conforto térmico no semiárido paraibano. 2018. Dissertação. 134f. (Mestrado em Arquitetura e Urbanismo) - Universidade Federal da Paraíba, João Pessoa, 2018.

TSUZUKI, K.; IWATA, T. Thermal comfort and thermoregulation for elderly people taking light exercise. In: INTERNATIONAL CONFERENCE ON INDOOR AIR QUALITY AND CLIMATE, 9., 2002, California. Proceedings [...] Rotterdam: Indoor Air, 2002. p.647-652.

TSUZUKI, K.; OHFUKU, T. Thermal sensation and thermoregulation in elderly compared to young people in Japanese winter season. In: INTERNATIONAL CONFERENCE ON INDOOR AIR QUALITY AND CLIMATE, 9., 2002, California. Proceedings [...] Rotterdam: Indoor Air, 2002. p.659-664.

VAN HOOF, J.; HENSEN, J. L. M. Thermal Comfort and Older Adults.Gerontechnology, v. 4, n. 4, p. 223-228, 2006. DOI: https://doi.org/10.4017/gt.2006.04.04.006.00

WHO. WORLD HEALTH ORGANIZATION. COP24 special report: Health and climate change. Geneva: World Health Organization, 2018.

\footnotetext{
${ }^{1}$ Raiana Spat Ruviaro

Arquiteta e Urbanista. Mestre em Engenharia Civil pela Universidade Federal de Santa Maria. Endereço postal: Avenida Roraima, n. 1000, Prédio 8, Sala 2061, Santa Maria, RS, Brasil, CEP 97.105-900
}

\section{${ }^{2}$ Bruna Zambonato}

Arquiteta e Urbanista. Mestranda em Arquitetura e Urbanismo no Programa de Pós-graduação em Arquitetura Urbanismo e Paisagismo da Universidade Federal de Santa Maria. Endereço postal: Avenida Roraima, n. 1000, Prédio 8, Sala 2058, Santa Maria, RS, Brasil, CEP 97.105-900

\section{${ }^{3}$ Giane de Campos Grigoletti}

Arquiteta e Urbanista. Doutorado em Engenharia Civil pela Universidade Federal do Rio Grande do Sul. Professora Associada na Universidade Federal de Santa Maria, Centro de Tecnologia, Departamento de Arquitetura e Urbanismo. Endereço postal: Avenida Roraima, n. 1000, Prédio 7, Dep. Arquitetura e Urbanismo, Santa Maria, RS, Brasil, CEP 97.105-900 